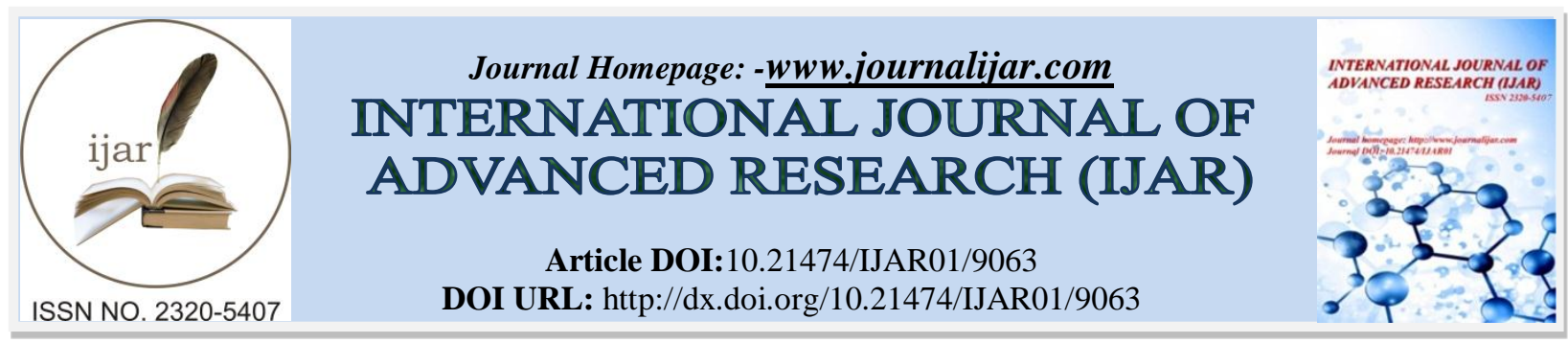

RESEARCH ARTICLE

\title{
PREVALENCE OF MECHANICAL LOW BACK PAIN AMONG BUS DRIVERS IN CAIRO TRANSPORT AUTHORITY IN EGYPT (SURVEY STUDY).
}

Ismail Mohamed Ismail1, Hamed Mohamed Elkhozamy and Salwa fadl Abd almegeed.

\section{Manuscript Info}

\section{Manuscript History}

Received: 14 March 2019

Final Accepted: 16 April 2019

Published: May 2019

\section{Key words:-}

prevalence, low back pain, bus drivers, musculoskeletal disorders.

1) B.Sc in physical therapy

Misr University for Science and

Technology

2) Lecturer the Department of

Musculoskeletal Disorder and It`s

Surgery Department

Faculty of Physical Therapy

Cairo University

3) Professor and Head the Department

of Musculoskeletal Disorder

and It`s surgery Department

Faculty of Physical Therapy

Cairo University

\begin{abstract}
Background: Mechanical low back pain MLBP) is an impacting musculoskeletal disorder. Hence, this study was commenced. Purposes: to acquire lifetime, MLBP among bus drivers who are currently working Cairo Transport Authority (CTA), as well as factors related to the workplace or the individual, and MLBP characteristics.

Methods: A specifically designed questionnaire was distributed to the bus drivers who are currently working in CTA (574 bus drivers). Results: all the bus drivers have completed the questionnaire. The lifetime prevalence of MLBP was $72.3 \%$ (95\% CI from $69.5 \%$ to $76.8 \%$ ), most prevalent bus drivers with MLBP were driving Emarat type bus $(52.3 \%)$.

Conclusion: Mechanical low back pain is common among Egyptian bus drivers at the prevalence, making CTA a high-risk group, which necessitate appropriate intervention to manage such sequelae.
\end{abstract}

Copy Right, IJAR, 2019,. All rights reserved.

\section{Introduction:-}

Mechanical low back pain (MLBP) is a major cause of illness and disability, especially in people of working age. 1. With a rapid transition to industrial lifestyle, LBP imposes a significant economic burden on governments, particularly in terms of health system costs, lost working days, reduced productivity and increased disability 2 Work-related LBP is estimated to cause 818,000 disability-adjusted life years lost (DALYs) annually 3 .

Professional drivers have been found to be at high risk of developing LBP due to prolonged sitting and vibratory exposure $_{4}$.

Low back pain arising from occupational ergonomic factors accounts for about one-third of all disability arising from the occupational risk factors included in the GBD 2010 project ${ }_{5}$.

Low back pain of vehicle drivers is mainly caused by long hours of driving in a restricted posture, car vibration or shocks from roads, and mental stress associated with driving 6 .

\section{Methodology: -}

Five hundred subjects with age range from 25-55 years. 
Inclusion criteria:

1. Five hundred currently working bus drivers in Cairo.

2. Age range from 25-55 years.

Exclusion criteria:

Subjects suffer from any physical disabilities before working as a bus driver in CTA.

\section{Instrumentations:}

Questionnaire based on Nordic questionnaire for LBP (Kuorinka, Jonsson etal.. 1987) with questions directed toward inquiring information related to driving work related LBP

\section{Experimental Procedures:}

1. Through a personal visit of the first author to the garages, the questionnaire was delivered personally to the drivers, and the researcher explained the aim of the study to the drivers, then the questionnaires were collected upon answering completion.

2. Informed consent of scientific publication of the questionnaire provided data was included as a part of the questionnaire.

\section{Results:-}

Lifetime prevalence of mechanical low back pain is $73,2 \%$ With $95 \%$ confidence that Lifetime prevalence of mechanical low back pain lies between $69.5 \%$ and $76.8 \%$.

\begin{tabular}{|l|l|l|l|}
\hline Garage & Frequency & Percent & Cumulative Percent \\
\hline Mezalat & 35 & 6.1 & 6.1 \\
\hline Obor & 32 & 5.6 & 11.7 \\
\hline Amiria & 32 & 5.6 & 17.2 \\
\hline Almostkbal & 31 & 5.4 & 22.6 \\
\hline Cairo & 31 & 5.4 & 28 \\
\hline Port said & 32 & 5.6 & 33.6 \\
\hline Athar alnaby & 35 & 6.1 & 39.7 \\
\hline Al teraa & 35 & 6.1 & 45.8 \\
\hline Al maady & 30 & 5.2 & 51 \\
\hline Al katamya & 30 & 5.2 & 56.3 \\
\hline Al sawaah & 34 & 5.9 & 62.2 \\
\hline Al matarya & 30 & 5.2 & 67.4 \\
\hline Al amal & 28 & 4.9 & 72.3 \\
\hline Fowm el khaleg & 28 & 4.9 & 77.2 \\
\hline Fatah & 35 & 6.1 & 83.3 \\
\hline Gesr el suez & 35 & 6.1 & 89.4 \\
\hline Nacr & 28 & 4.9 & 94.3 \\
\hline Al basaten & 33 & 5.7 & 100 \\
\hline total & 574 & 100 & \\
\hline
\end{tabular}

Table 1:-Subjects characteristics

\begin{tabular}{|c|c|c|c|c|c|}
\hline \multicolumn{6}{|l|}{ Age } \\
\hline \multicolumn{3}{|c|}{ Ranged from 28 to 59 years } & \multicolumn{3}{|c|}{ Average of $40.24( \pm 0.62)$} \\
\hline \multicolumn{6}{|c|}{ Body Mass Index } \\
\hline \multicolumn{3}{|c|}{ Ranged from19.59 to 45.52 years } & \multicolumn{3}{|c|}{ Average of $27.42( \pm 0.4)$} \\
\hline \multicolumn{6}{|l|}{ Kind of bus } \\
\hline & VOLVO & MARCEDIES & EMARAT & IVECO & NASR \\
\hline Percentage & $5.10 \%$ & $31.40 \%$ & $52.30 \%$ & $7.30 \%$ & $4.00 \%$ \\
\hline \multicolumn{6}{|l|}{ Experience } \\
\hline \multicolumn{3}{|c|}{ Ranged from1 to 33.5 years } & \multicolumn{3}{|c|}{ Average of $12.25( \pm 0.59)$ years } \\
\hline
\end{tabular}




\section{Ranged from 25 to 80 hours/week}

Average of $\mathbf{5 7 . 4 9 ( \pm 0 . 6 9 )}$ hours/week

Table 2:-Factors related to workplace or other individual

\begin{tabular}{|c|c|c|c|c|c|}
\hline \multicolumn{6}{|l|}{ Age } \\
\hline Classes (years) & less than 29 & $29.00-34.20$ & $34.21-40.40$ & $40.41-46.60$ & More than 46.61 \\
\hline Percentage & 2.4 & 20.7 & 36.6 & 17.1 & 23.2 \\
\hline \multicolumn{3}{|l|}{ Mean (SD) } & \multicolumn{3}{|l|}{$40.24 \pm 0.62$} \\
\hline \multicolumn{6}{|c|}{ Work-related LBP onset since starting work as a driver } \\
\hline Class (Y) & $\leq 7.5$ & $7.51-14.00$ & $14.01-20.50$ & $20.51-27.00$ & More than 27.01 \\
\hline Percentage & 30.5 & 36.6 & 18.3 & 12.2 & 2.4 \\
\hline \multicolumn{3}{|l|}{ Mean (SD) } & \multicolumn{3}{|l|}{$12.25 \pm 0.59$} \\
\hline \multicolumn{6}{|c|}{ Body Mass Index of P.Ts with LBP } \\
\hline Class & $19.51-24.70$ & $24.71-29.90$ & $29.92-35.11$ & $35.12-40.31$ & More than 40.32 \\
\hline Percentage & 41.5 & 32.9 & 18.3 & 4.9 & 2.4 \\
\hline \multicolumn{3}{|l|}{ Mean (SD) } & \multicolumn{3}{|l|}{$27.42 \pm 0.40$} \\
\hline \multicolumn{6}{|c|}{ Number of hours of driving per week when first LBP was experienced } \\
\hline Class (h) & less than 40.00 & $40-54$ & 55- 69 & More than 70.00 & \\
\hline Percentage & 3.7 & 30.5 & 58.5 & 7.3 & \\
\hline \multicolumn{3}{|l|}{ Mean (SD) } & \multicolumn{3}{|l|}{$57.49 \pm 0.69$} \\
\hline
\end{tabular}

Table 3:-Work-related LBP Characteristics

\section{Onset}

\begin{tabular}{|c|c|c|c|c|c|}
\hline & None & \multicolumn{2}{|l|}{ Sudden } & \multicolumn{2}{|l|}{ Gradual } \\
\hline Percentage & 26.8 & \multicolumn{2}{|l|}{8.5} & \multicolumn{2}{|l|}{64.6} \\
\hline \multicolumn{6}{|c|}{ Mechanisms of Injury } \\
\hline Percentage & 26.8 & 3.7 & 4.9 & 59.8 & 4.9 \\
\hline \multicolumn{6}{|c|}{ Lifetime intensity of LBP } \\
\hline & None & Mild & Moderate & Severe & \\
\hline Percentage & 26.8 & 11 & 30.49 & 31.71 & \\
\hline
\end{tabular}

\begin{tabular}{|c|c|c|c|c|c|}
\hline \multicolumn{6}{|c|}{ Recurrence of LBP } \\
\hline & None & Once & Recurrent & & \\
\hline Percentage & 26.8 & 7.3 & 65.9 & & \\
\hline \multicolumn{6}{|c|}{ Hospitalization because of WRLBP } \\
\hline & \multicolumn{2}{|l|}{ Yes } & \multicolumn{2}{|l|}{ No } & \\
\hline Percentage & \multicolumn{2}{|l|}{9.76} & \multicolumn{2}{|l|}{90.24} & \\
\hline \multicolumn{6}{|c|}{ Consultation or medical examination } \\
\hline & \multicolumn{2}{|l|}{ Yes } & \multicolumn{2}{|l|}{ No } & \\
\hline Percentage & \multicolumn{2}{|l|}{61} & \multicolumn{2}{|l|}{39} & \\
\hline \multicolumn{6}{|c|}{ Treatment or intervention because of $\mathrm{LBP}$} \\
\hline Percentage & 26.8 & 7.3 & 25.6 & 29.3 & 11 \\
\hline \multicolumn{6}{|c|}{ Retiring consideration because of WRLBP } \\
\hline & \multicolumn{2}{|c|}{ Yes } & \multicolumn{2}{|l|}{ No } & \\
\hline Percentage & \multicolumn{2}{|l|}{24.4} & \multicolumn{2}{|l|}{75.6} & \\
\hline \multicolumn{6}{|c|}{ Surgery consideration for the WRLBP } \\
\hline & \multicolumn{2}{|l|}{ Yes } & \multicolumn{2}{|l|}{ No } & \\
\hline Percentage & \multicolumn{2}{|l|}{3.7} & \multicolumn{2}{|l|}{96.3} & \\
\hline
\end{tabular}

\section{Discussion:-}

Our descriptive survey-based study aimed to the acquiring of work-related low back pain Lifetime prevalence, height, age, years of driving, weakly hours, body mass index among CTA bus drivers 


\section{The outcomes measured were as follows: - Lifetime prevalence: -}

Our study identified Lifetime prevalence of MLBP as $73.2 \%$ and surpasses the outcomes of drivers 'in the UAE 7 with $40.8 \%$, in Nigeria $_{8}$ with $58.5 \%$, in Korea $93.7 \%$ and in Israel 10 It was found that $45.4 \%$ of drivers had experienced with lower back pain, Studies conducted in the UK, Taipei , and Sweden reported LBP prevalence rates of $60 \%{ }_{11}, 51 \% \quad 12$, and $81 \%{ }_{13}$ (Magnusson et al., 1996) among truck, taxi, and bus drivers, respectively. In Brazil 13 evaluated 410 truck drivers and found that the prevalence of low back pain/discomfort amongst the sampled population was $59 \%$ with daily working hours being its highest prevalence.

The lifetime incidence of an acute episode of LBP ranges from $60 \%$ to $90 \%$, and $30 \%$ of those with LBP may develop a chronic condition 14 .

As in Egypt the roads are so crowded and the drivers in a public transport society don't do any sports activities and it's not in their culture doing stretches or flexibility exercises and there is a lack of ergonomic knowledge while driving

\section{Height: -}

In our study drivers who are above $181 \mathrm{~cm}$ height represent the highest proportional of their peers' drivers at same height as in 15 body height of at least $180 \mathrm{~cm}$ for men was a predictor of being diagnosed with herniated lumbar intervertebral discs and in ${ }_{16}$ a British retrospective study of lifetime risk of LBP, men with a height of $184 \mathrm{~cm}$ or more had double the risk of those who were $170 \mathrm{~cm}$ or shorter

Age: -

In our study drivers age range from 34.21 - 40.40 years old were the highest complain of LBP as in 8 , age range was 25-44 years old while in 17 age range was $41.07 \pm 8.10$ years old . back pain was more common among adults over the age of 45 18.

\section{Years of driving: -}

In our study driving for 7.5 to 15 years is significantly associated with increased LBP while in UAE 7 (years of driving $>10$ years, are significantly associated with increased LBP, Nigeria 8 ,

Driving experience 17.75 are significantly associated with increased LBP and in Korea 9 years of driving were $10.17 \pm 7.82$ years.

\section{Weakly hours: -}

In our study driving for more than 60 hours per week is significantly associated with increased LBP As in Nigeria 8 , and Korea 9. While in UAE ${ }_{7}$, driving for more than 40 hours per week is significantly associated with increased LBP. 19 also found that driving $.20 \mathrm{~h} /$ week for work was associated with high frequency of low back trouble and related sickness absence.

\section{Retirement from driving: -}

In our study $33.3 \%$ of the drivers complained from LBP considered retirement surpasses in Nigeria ${ }_{8}$ (Rufa'I et al., 2015) $29 \%$ considered retirement

${ }_{20}$ A survey among 500 farmers in rural Nigeria showed that more than half reduced their farming workload because of low back pain and, In Zimbabwe 21 low back pain was among the top five reported primary health complaints, and reasons for activity limitation.

\section{Body mass index: -}

In our study $38.3 \%$ of the complained drivers from LBP are in 25-29.9 BMI, while in Norway 22 was $50.6 \%$ the complained men from LBP are in 25-29.9 BMI and in Portuguese ${ }_{23}$ BMI $>25 \mathrm{~kg} / \mathrm{m}^{2}$ ) was a factor significantly and independently associated with active LBP.

obesity has been shown as a risk factor for disk degeneration and may increase the prevalence of LBP 24 


\section{Conclusion:-}

Bus drivers working in CTA are at a high-risk of developing LBP, which is recurrent, with risk factors that require special consideration as, workplace specialty, hazardous tasks like bending and twisting and early years of practice.

\section{Conflict of Interest:}

None

\section{References:-}

1. Endean, A., Palmer, K. T., \& Coggon, D. (2011). Potential of MRI findings to refine case definition for mechanical low back pain in epidemiological studies: a systematic review. Spine, 36(2), 160.

2. Gouveia, N., Rodrigues, A., Eusébio, M., Ramiro, S., Machado, P., Canhão, H., \& Branco, J. C. (2016). Prevalence and social burden of active chronic low back pain in the adult Portuguese population: results from a national survey. Rheumatology international, 36(2), 183-197.

3. Punnett, L., Prüss-Ütün, A., Nelson, D. I., Fingerhut, M. A., Leigh, J., Tak, S., \& Phillips, S. (2005). Estimating the global burden of low back pain attributable to combined occupational exposures. American journal of industrial medicine, 48(6), 459-469.

4. Funakoshi, M., Taoda, K., Tsujimura, H., \& Nishiyama, K. (2004). Measurement of whole-body vibration in taxi drivers. Journal of occupational health, 46(2), 119-124.

5. Hoy, D., March, L., Brooks, P., Blyth, F., Woolf, A., Bain, C., ... \& Murray, C.

6. (2014). The global burden of low back pain: estimates from the Global Burden of Disease 2010 study. Annals of the rheumatic diseases, annrheumdis-2013.

7. Jaiswal, A.(2013). Low Back Pain and Work-Related Risk Factors among Drivers of Pondicherry. International Journal of ScientificFootprints, 1(2): 7-16.

8. Ebinouff, N., \& Alnajeb, O. (2018). 192 Prevalence of back pain in professional drivers in abu dhabi.

9. Rufa'i, A. A., Sa'idu, I. I. A., Ahmad, R. I. Y., Elmi, O. S., Aliyu, S. U., Jajere, A. M., \& Digil, A. A. (2015). Prevalence and risk factors for low back pain among professional drivers in Kano, Nigeria. Archives of environmental \& occupational health, 70(5), 251-255.

10. Lee, J. H., \& Gak, H. B. (2014). Effects of self stretching on pain and musculoskeletal symptom of bus drivers. Journal of physical therapy science, 26(12), 1911-1914.

11. Alperovitch-Najenson, D., Santo, Y., Masharawi, Y., Katz-Leurer, M., Ushvaev, D., \& Kalichman, L. (2010). Low back pain among professional bus drivers: ergonomic and occupational-psychosocial risk factors. Sat, 2,18 .

12. Robb, M. J., \& Mansfield, N. J. (2007). Self-reported musculoskeletal problems amongst professional truck drivers. Ergonomics, 50(6), 814-827.

13. Chen, J. C., Chang, W. R., Chang, W., \& Christiani, D. (2005). Occupational factors associated with low back pain in urban taxi drivers. Occupational Medicine, 55(7), 535-540.

14. Andrusaitis, S. F., Oliveira, R. P., \& Barros Filho, T. E. P. (2006). Study of the prevalenceand risk factors for low back pain in truck drivers in the state of São Paulo,Brazil. Clinics, 61(6), 503-510.

15. Harris, G. R., \& Susman, J. L. (2002). Managing musculoskeletal complaints with rehabilitation therapy: summary of the Philadelphia Panel evidence-based clinical practice guidelines on musculoskeletal rehabilitation interventions. Journal of family practice, 51(12), 1042-1048.

16. Heliövaara, M. A. R. K. K. U. (1987). Body height, obesity, and risk of herniated lumbar intervertebral disc. Spine, 12(5), 469-472.

17. Walsh, K., Cruddas, M., \& Coggon, D. (1991). Interaction of height and mechanical loading of the spine in the development of low-back pain. Scandinavian journal of work, environment \& health, 420-424.

18. Odebiyi, D. O., Ogwezi, D. C., \& Adegoke, B. O. (2009). The prevalence of low back pain in commercial motor drivers and private automobile drivers.

19. Nigerian journal of medical rehabilitation, 12(1 and 2), 21-24.

20. Deyo, R. A., Mirza, S. K., \& Martin, B. I. (2006). Back pain prevalence and visit rates: estimates from US national surveys, 2002. Spine, 31(23), 2724-2727.

21. Porter, J. M., \& Gyi, D. E. (2002). The prevalence of musculoskeletal troubles among car drivers. Occupational Medicine, 52(1), 4-12.

22. Fabunmi, A. A., Aba, S. O., \& Odunaiya, N. A. (2005). Prevalence of low back pain among peasant farmers in a rural community in South West Nigeria. African journal of medicine and medical sciences, 34(3), 259-262. 
23. Jelsma, J., Mielke, J., Powell, G., Weerdt, W. D., \& Cock, P. D. (2002). Disability in an urban black community in Zimbabwe. Disability and Rehabilitation, 24(16), 851-859.

24. Heuch, I., Heuch, I., Hagen, K., \& Zwart, J. A. (2015). Association between body height and chronic low back pain: a follow-up in the Nord-Trøndelag Health Study. BMJ open, 5(6), e006983.

25. Gouveia, N., Rodrigues, A., Eusébio, M., Ramiro, S., Machado, P., Canhão, H., \& Branco, J. C. (2016). Prevalence and social burden of active chronic low back pain in the adult Portuguese population: results from a national survey. Rheumatology international, 36(2), 183-197.

26. Biglarian, A., Seifi, B., Bakhshi, E., Mohammad, K., Rahgozar, M., Karimlou, M., \& Serahati, S. (2012). Low back pain prevalence and associated factors in Iranian population: findings from the national health survey. Pain research and treatment, 2012. 